\title{
Contribuição para o estudo do Direito Comparado do Trabalho Alemão-Bra- sileiro na parte relativa aos Acidentes do Trabalho *
}

\author{
Nair Lemos Gonçalves \\ Assistente do Seminário de Legislação Social \\ anexo à Cadeira de Legislação Social, da \\ Faculdade de Direito da Universidade de \\ São Paulo.
}

Tendo recebido a honrosa incumbência de cuidar da parte referente à Infortunística neste Curso, que se reveste de caráter experimental, como primeira manifestação do recém-criado Instituto de Direito Comparado do Trabalho, anexo à Cadeira de Legislação Social desta Faculdade, cabe-nos de início esclarecer que esta contribuição pretende limitar-se à simples exposição de fatos, tais como ocorrem nas duas áreas comparadas, primeiro e necessário passo, pois, para futuras indagacões sôbre os motivos de ordem social, ideológica ou econômica que possam explicar as diferenças de orientação e conceituação assinaladas.

\section{I - Legislação}

No Brasil, as normas sôbre acidentes do trabalho encontram-se no Decreto-lei n. ${ }^{\circ} 7.036$, de 10 de novembro

(*) Aula proferida no dia 1.\%/10/59, no Curso de Extensão Universitária sôbre "Aspectos do Direito Comparado do Trabalho Alemão-Brasileiro", realizado pela Faculdade de Direito da Universidade de São Paulo, sob a responsabilidade do Prof. A. F. Cesarino Júnior. 
de 1944, com as alterações e regulamentos posteriores, completado pelas portarias do Servico Atuarial, do Ministério do Trabalho, Indústria e Comércio, e pelos dispositivos referentes à higiene e segurança do trabalho, constantes da Consolidação das Leis do Trabalho.

Nossa Constituição Federal determina, em seu art. 157, além de outras disposições sôbre proteção do trabalho, que a legisislação deverá observar, o preceito da

"Xvil - obrigatoriedade do seguro pelo empregador contra os acidentes do trabalho;",

cabendo privativamente à União, na conformidade do art. 5.", n. ${ }^{\circ} \mathrm{XV}$, letras "a" e "b", legislar sôbre o direito do trabalho, bem como sôbre normas gerais de seguro e previdência social.

$\mathrm{Na}$ Alemanha, a infortunística constitui objeto de um dos seguros sociais, desde o tempo de Bismarck, quando, em 1884, foi baixado o "Unfallversicherungsgeseltz" (Lei do seguro de acidente), que, posteriormente, passou a integrar o Livro $3 .^{\circ} \mathrm{da}$ "Reichsversicherungsordnung" (Código de Seguros do Reich), de 1911.

Após a 2." Guerra Mundial, realizou-se na então zona soviética reforma geral dos seguros sociais (inclusive, portanto, o de acidentes), pela Ordem n. ${ }^{\circ} 28$, de 28 de janeiro de 1947, do Govêrno Militar, completada pela Ordenação de 9 de abril do mesmo ano, expedida pela administração alemã do trabalho.

A Constituição da República Democrática Alemã, de 8 de outubro de 1949, assim determinou em seu artigo 16, n. 3 :

"Mediante um regime uniforme e completo de seguros sociais, administrado em forma autônoma pelos segurados mesmos, proteger-se-á a saúde e a manutenção da capacidade de trabalho do povo laborioso, assim como a materni- 
dade, e prever-se-ão as consequências econômicas da velhice, da incapacidade, da falta de trabalho e outras vicissitudes da existência. "(in "Série Legislativa", jan.-fev. de 1951)

A seguir, a Ordenação de 26 de abril de 1951 e o regulamento expedido em 10 de dezembro de 1952 pela Confederação Livre dos Sindicatos Alemães introduziram alterações na reforma geral operada em 1947, sendo êste o regime atualmente vigente na Alemanha Oriental.

Na Alemanha Ocidental a reforma dos seguros sociais está ainda em elaboração e tem por objetivo substituir a "Reichsversicherungsordnung" lá ainda em vigor com numerosas alterações, por um novo Código de Seguros Sociais, que deverá atender às modificações da estrutura econômica e da sociedade, que se vêm processando nesses 70 anos já decorridos desde os tempos do Conselheiro de Ferro.

A Constituição da República Federal da Alemanha, de 23 de maio de 1949 , no art. 74, n. $^{\circ} 12$, incluiu na competência concorrente da Federação e dos Estados (Länder) a matéria relativa ao

"direito do trabalho, compreendendo a organização de emprêsas, a proteção dos operários e a obtenção de trabalho, assim como os seguros sociais, inclusive o seguro de desemprêgo;" (in "Série Legislativa" jan.-fev. de 1951)

Segundo o art. 72 da mesma Constituição, no terreno da competência concorrente, os Estados podem legislar " $s i$ et in quantum" a Federação não exerce sua faculdade.

Assim, disciplinam a Infortunística na Alemanha Ocidental o antigo Código de Seguros do Reich (muito modificado por numerosas leis posteriores), as normas de prevenção de acidentes (Unfallverhütungsvorschriften), expedidas pelas seguradoras, com aprovação do Govêrno e as 
chamadas "Satzungen", que são normas expedidas pelas seguradoras no exercício do "autonomes Satzungsrecht", que lhes garante o Código de Seguros, desde que respeitem condições mínimas fixadas na lei.

\section{II - Conceito de acidente do trabalho}

Através das definições contidas nos artigos $1 .^{\circ} \mathrm{e} 2 .^{\circ} \mathrm{da}$ nossa Lei de Acidentes, bem como das outras disposições do Capítulo I, são três os elementos indispensáveis para configuração do acidente do trabalho: $1 .^{\circ}$ ) dano corporal; $\left.2 .^{\circ}\right)$ nexo etiológico entre o dano e o trabalho; e $3 .^{\circ}$ ) incapacidade ou morte. Tratando-se de relação jurídica entre empregador e empregado (exceto o caso do presidiário), há ainda um elemento preexistente - o contrato de trabalho.

Não conseguimos o texto da legislação hoje em vigor na República Democrática Alemã e, por isso, faremos agora comparação apenas com o Código de Seguros da Alemanha Ocidental.

A "Reichsversicherungsordnung" não contém definição completa de acidente do trabalho (Arbeitsunfall). Assim dispõem os seus $\S \S 542,543,545$ e 555 :

“§ 542. (1) Os acidentes do trabalho são os acidentes de que os segurados são vitimas no curso das ocupações previstas nos $\S \S 537$ a 540 .

(2) $O$ fato de um ato ter sido praticado apesar de existir interdição, não tem o efeito de excluir a presunção de um acidente do trabalho.

$\S 543$. (1) São igualmente considerados como acidentes do trabalho os acidentes ocorridos quando o segurado se dirige para o lugar de trabalho ou para o lugar onde êle recebe sua formação para as necessidades de sua atividade 
na emprêsa, ou na volta. O fato de, em razão da distância entre seu, domicilio familiar permanente e o lugar de seu trabalho ou de sua formação, o segurado ter um alojamento no lugar do trabalho ou nas suas proximidades, não exclui o seguro entre êste lugar e o domicílio familiar.

“§ 545. (1) O govêrno do Reich poderá, por via de ordenação, designar certas moléstias como moléstias profissionais. As prescrições do seguro de acidentes se aplicarão a estas moléstias, quer seja a moléstia devida a um acidente ou a uma influência nociva que não apresente o caráter de um acidente.

(2) O govêrno do Reich poderá regulamentar a aplicação do seguro de acidentes no caso de moléstia profissional, bem como o modo e as condições de reparação. (in "Série Legislativa" out.-dezembro de 1943).

“ $§ 555$. O objeto do seguro é a indenização, determinada nos preceitos seguintes, do prejuízo resultante de lesão corporal, morte ou danificação de aparelho de prótese. (in "Reichsversicherungsordnung” -- 39. Auflage. Bearbeitet von Karl Klöpfer - 1951 - W. Kohlhammer Verlag - Stuttgart).

Do confronto dêsses dispositivos, verificamos que as principais diferenças, relativamente à lei brasileira, são as seguintes:

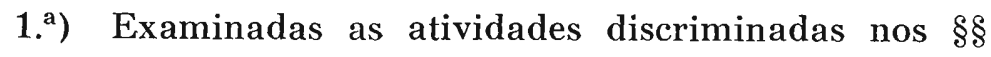
537 a 540 , verifica-se que nem sempre se exige na Alemanha o contrato de trabalho, pois há vários casos em que não existe a dependência econômica ou nos quais a ativi- 
dade é exercida em caráter puramente eventual. Citemos, por exemplo, as atividades voluntárias de salvamento, de doação de sangue, de auxílio a policiais, de defesa a pessoas injustamente atacadas e os trabalhos prestados a título honorário nas escolas profissionais.

2. $\left.{ }^{a}\right)$ Admite a lei alemã que possa caracterizar-se o acidente, não só através de dano corporal, como no Brasil, mas também no caso especial de dano material de aparelhos de prótese.

Cabe lembrar aqui que, examinando o mesmo problema, Barassi (in "Previdenza Sociale e Lavoro Subordinato, vol. I, p. 304/305) esclarece que, embora a lei italiana de 1935 (Decreto Real de 17-8-935) não mais faça referência expressa a lesão pessoal, como a antiga lei de 1904, ainda assim a jurisprudência continua a responder negativamente, quando se trata de indenizaçâo por dano em aparelhos de prótese, entendendo que o conceito antigo existe implícito na lei nova, tanto que esta só se refere a tais aparelhos como prestação ao acidentado.

$\mathrm{Na}$ vigência do Decreto $n .^{\circ} 24.637$, de 10-7-1934, a $3 .^{\mathrm{a}}$ Câmara Civil do então Tribunal de Apelação de São Paulo, em aresto publicado na Revista dos Tribunais, vol. 125/511, decidiu unânimemente que

“Acidente no trabalho é sempre, e só, uma lesão corporal ou doença, e a quebra de um aparelho protético não é uma lesão corporal e muito menos doença."

Nesta parte não trouxe qualquer inovação o art. $1 .^{\circ}$ da atual Lei de Acidentes, tendo nesse sentido se manifestado a $4 .{ }^{\text {a }}$ Câmara Civil do Tribunal de Justiça do Distrito Federal, por acórdão de 7-6-49, ao decidir que

"Não é indenizável o acidente do trabalho de que não resulte lesão física nem diminuição da 
capacidade laborativa do acidentado. "(in Revista Forense, vol. cxxxı, p. 442).

Tulio Marques Lopes, esclarecendo que se trata de questão controvertida, opina em recente parecer pela possibilidade da indenização, invocando justamente o fato de que "se o trabalhador tem direito, até, a receber além da indenização aparelho protético, que lhe diminua a incapacidade, quando necessário, nos têrmos do art. 28 do dec.-lei n. ${ }^{\circ}$ 7.036, citado, como se sustentar, coerentemente, que não lhe cabe ver restaurado o aparelho que já possua." (in Revista Forense, vol. 174, p. 104). Vemos aqui que o mesmo argumento apontado pela jurisprudência italiana para não conceder indenização por dano material é alegado para justificá-la.

$\left.3 .^{a}\right)$ A Alemanha só admitiu a indenização de doenças profissionais (Berufskrankheiten) de acôrdo com as normas próprias do acidente do trabalho a partir de 1925. O primeiro catálogo de doenças profissionais apresentou 11 moléstias. A discriminação foi alterada em 1929, 1936, 1943 e, finalmente, em 1952, pela Ordenação n. ${ }^{\circ}$ 5, de 26 de julho, que enumerou 40 doenças.

Com o sistema atual não é possível portanto cuidar na Alemanha de indenização de moléstias profissionais atípicas, como acontece entre nós. (Lembre-se que não têm sido poucas as divergências surgidas em nosso país, relativamente ao reconhecimento, como acidente do trabalho, de doenças como a tuberculose, por exemplo, em que os tisiólogos, de um lado, negam a existência do nexo etiológico, na maioria dos casos, e os peritos, baseados principalmente no art. $3 .^{\circ}$ da lei, não vêem como negar a existência de relação de causa e efeito entre a moléstia e o trabalho, quando êste, por qualquer forma, contribuiu para a eclosão ou agravamento do mal.)

Este assunto vem sendo discutido na Alemanha, onde surgiu corrente de opinião favorável, não à alteração da 
leı para autorizar genèricamente a indenização de moléstias profissionais atípicas, mas apenas para dar às seguradoras a faculdade de, no caso concreto, reconhecer como moléstia profissional doença não incluída na tabela, desde que os conhecimentos e a experiência da ciência médica ou o desenvolvimento técnico possam apontá-la como consequência de riscos a que os trabalhadores estejam sujeitos muito mais do que a população em geral.

4. $\left.{ }^{a}\right)$ Ao passo que a lei brasileira admite o acidente "in itinere" apenas nos casos de condução fornecida pelo empregador ou quando o caminho of ereça reais perigos, a que não esteja sujeito o público em geral, a lei alemã não faz qualquer restrição nesse sentido: exige apenas, segundo a jurisprudência, que o caminho não tenha sido alterado ou o trajeto interrompido por motivo de ordem particular do empregado.

Situação semelhante ocorre na França. Temos notícia de acórdão recente em que o Tribunal de Cassação francês negou ter ocorrido acidente do trabalho "in itinere" em determinado caso, porque o acidentado, embora retornasse ao trabalho, não vinha de sua residência, mas de um restaurante, onde tomara refeição (in "I.N.A.I.L." n. ${ }^{\circ}$ 21-22 - nov.-dezembro de 1957, p. 533). (Fáceis de imaginar as dificuldades que surgiriam no Brasil, se adotado o mesmo princípio. Poderíamos ver talvez tentativas de exclusão do acidente do trabalho, quando o evento se verificasse, por exemplo, na rua Líbero Badaró, sob alegação de que o caminho a ser percorrido para atingir o largo de São Bento deveria ter sido a rua de São Bento, ou, no outro extremo, esforços para provar que, saindo do Largo de São Francisco em direção à Avenida Brigadeiro Luiz Antonio, estaria o empregado percorrendo caminho de acesso ao Largo de São Bento, porque faria volta pela rua Asurubal do Nascimento!!!) 


\section{III — Seguro de acidentes do trabalho}

Na Alemanha, como no Brasil, é obrigatório o seguro contra riscos de acidente do trabalho, pago exclusivamente pelo empregador.

Os órgãos seguradores, na República Federal da Alemanha, são as associações mútuas profissionais de empregadores (Berufsgenossenschaften) e as associações municipais de seguro de acidente (Gemeindeunfallversicherungsverbände). Existem ainda órgãos de seguro federais, estaduais ou municipais, que se encarregam da chamada Eigenunfallversicherung, isto é, seguro de acidentes feito pelo próprio chefe, os quais são responsáveis pelos acidentes ocorridos, respectivamente, por empregados federais, estaduais ou municipais; pelos ocorridos nos serviços de incêndio, bem como por aquêles que se verificarem em atividades exercidas sem a existência de contrato de trabalho.

As associações de seguro, durante o regime nazista, estiveram sujeitas ao contrôle integral do Estado, que nomeava diretórios e conselhos encarregados de sua administração.

Com a lei federal de 22 de fevereiro de 1951, restabeleceu-se a autonomia das instituições do seguro social (inclusive, o de acidentes), passando elas a ter como órgãos de direção os respectivos Comités Diretivos e Assembléias de Delegados, integrados por representantes dos segurados e dos empregadores, em igual número, com exceção das seguradoras do trabalho agrícola, nas quais $1 / 3$ de representantes é de empregadores, $1 / 3$ de segurados e $1 / 3$ de trabalhadores autônomos e nas dos mineiros, nas quais $2 / 3$ é de representantes de segurados e $1 / 3$ dos empregadores.

Na República Democrática Alemã, de acôrdo com o art. 15, $\mathrm{n}^{\circ} 3$, da Constituição, o sistema de seguro social 
está sob jurisdição exclusiva dos sindicatos, através da Confederação Livre dos Sindicatos Alemães.

Criou-se na Alemanha Oriental um Instituto Central de Seguro Social e o Conselho Central de Seguro Social, encarregado de executar a política fixada pela Confederação. Nas diversas regiões (Bezirke) e nos distritos (Kreise) existem Conselhos semelhantes ao Central.

As contribuições são pagas pelos empregadores juntamente com os impostos e arrecadadas pelo Govêrno, ao contrário do que aconteceu até 1951, quando o recolhimento era feito nas próprias instituições de seguro.

Observamos, portanto, que a mudança de regime político na Alemanha Ocidental acarretou o retôrno à antiga tradição de autonomia existente antes do nazismo, ao passo que na República Democrática fêz passar o seguro das mãos do govêrno para as dos próprios segurados.

No Brasil, como todos sabem, a Lei de Acidentes em vigor, baixada na vigência da Carta Constitucional de 1937, quis estabelecer o regime de monopólio do seguro de acidente pelas instituições de previdência social. Até hoje, entretanto, apenas o Instituto de Aposentadoria e Pensões dos Marítimos e o I.A.P.E.T.c. possuem a exclusividade. $O$ prazo fixado para as entidades particulares continuarem a operar em seguro contra riscos de acidente do trabalho, após a mudança do regime político entre nós, foi dilatado com têrmo certo pelả Lei 599-A, de 26 de dezembro de 1948, tendo depois a Lei n. ${ }^{\circ} 1985$, de 19 de setembro de 1953, adiado "sine die" a concessão da exclusividade às demais instituições de previdência.

Assim, enquanto na Alemanha o seguro de acidentes é um dos ramos do seguro social, no Brasil continua êle a ser operado com fim de lucro, que constitui sem dúvida uma das características do seguro privado.

Mas a diferença que reputamos essencial entre o seguro de acidentes alemão e o brasileiro diz respeito exa- 
tamente às atribuições dos órgãos seguradores, da República Federal da Alemanha.

A tarefa mais importante do seguro de acidentes e, consequentemente, dos órgãos seguradores da Alemanha Ocidental é a prevenção. Para isso e como instrumentos da prevenção, têm êles o direito e o dever de expedir normas jurídicas objetivas, sob a forma de instruções sôbre medidas preventivas (Unfallverhütungsvorschriften), que os empresários devem executar, e normas de comportamento que os segurados devem observar para evitar acidentes. Tão importantes são estas instruções que para elas a lei exige aprovação dos órgãos competentes do Estado.

A prevenção é realizada, portanto, através da atividade das seguradoras, das autoridades estatais de fiscalização e, finalmente, dos próprios empregadores e empregados.

Cabe também às seguradoras, além da assistência médica, farmacêutica e hospitalar, bem como das prestações em dinheiro, o trabalho de reabilitação do acidentado, que inclui o treinamento profissional para que possa êle readquirir a capacidade de ganho, prejudicada pelo acidente, ou a formação para uma nova profissão, na hipótese de a lesão sofrida impedir o exercício da profissão anterior.

No Brasil a lei cuida no Capítulo XII da prevenção de acidentes e da higiene do trabalho, atribuindo a responsabilidade aos empregadores, aos órgãos competentes do Ministério do Trabalho e às comissões internas de prevenção de acidentes (c.I.P.A.s.), cuja criação, pelos empregadores, é determinada no artigo 82.

A readaptação profissional e o reaproveitamento do acidentado previstos no Capítulo XIV são trabalhos cometidos a serviços e escolas profissionais especiais que nenhuma relação obrigatória têm com as seguradoras. 
Talvez se possa explicar até certo ponto a diferença, pois, ao passo que no Brasil as seguradoras não são órgãos de que façam parte obrigatòriamente os empregadores, na República Federal da Alemanha são elas associações dos próprios empregadores.

\section{IV - Prestações aos acidentados}

1. República Federal da Alemanha. De acôrdo com o $§ 558$ da "Reichsversicherungsordnung", as prestações em utilidades são as seguintes:

a) Tratamento do doente (Krankenbehandlung), que compreende a assistência médica, farmacêutica, hospitalar, dentária, bem como todos os meios de socôrro necessários para assegurar o tratamento ou para diminuir as consequências da lesão. É prevista também a assistência aos acidentados que se tornaram incapazes de dispensar o auxílio alheio para satisfazerem a numerosas das necessidades da vida diária e que é prestada por enfermeiras no domicílio do acidentado, ou em outros lugares adequados para onde êle é removido. Esta assistência pessoal pode ser substituida pelo pagamento ao segurado de uma importância em dinheiro, que varia entre 75 e 275 DM mensais. Esse pagamento corresponde ao acréscimo de indenização concedido, entre nós, pelo $\S 3 .^{\circ}$ do art. 17, da Lei de Acidentes, nos casos de cegueira total, perda ou paralisia de ambos os membros superiores ou inferiores e alienação mental.

b) Reabilitação do acidentado (Berufsfürsorge), que consiste no treinamento profissional e tôdas as medidas necessárias à recuperação da capacidade profissional e, se fôr o caso, a formação para uma nova profissão.

c) Reparação ou substituição de aparelhos protéticos (Körperersatzstück).

As prestações em dinheiro compreendem: 
a) Auxílio-doença (Krankengeld). A partir do $1 .^{\circ}$ dia de incapacidade, os acidentados, que também pertencem a Caixas de Seguro-Doença, começam a receber destas Caixas o auxílio-doença que, geralmente, é pago até a $26{ }^{2}$ semana. O pagamento pode estender-se até o prazo de um ano, ou mais ainda, em certas condições, quando, segundo parecer médico, é provável a recuperação da capacidade de trabalho em determinado lapso de tempo.

Nas primeiras seis semanas, a auxílio-doença corresponde a $65 \%$ do salário do acidentado, podendo ser acrescido através de suplementos familiares. Os empregados (Angestellten), quando não tenham culpa da incapacidade de trabalho que sofreram, recebem, além do auxílio-doença e durante as seis primeiras semanas, o seu salário, pago pelo empregador. Os operários (Arbeiter), desde que a serviço ininterrupto do empregador há, pelo menos, 4 semanas, terão direito, também durante as seis primeiras semanas, a um suplemento igual à diferença entre o auxílio-doença e $90 \%$ de seu salário, pago pelo empregador.

A partir da $7 .^{a}$ semana, desce o auxílio-doença para $50 \%$ do salário, podendo atingir no máximo $75 \%$, através de suplementos familiares $(10 \%$ do salário para a espôsa e $5 \%$ para cada um dos dependentes restantes, até o limite máximo permitido).

Os segurados que não tiverem direito a auxílio-doença pago pela Caixa de Seguro-Doença, recebem uma renda, do seguro de acidentes, a partir do $1 .^{\circ}$ dia de incapacidade. A seguradora pode, ao invés de renda, conceder-lhes auxílio-doença nas mesmas condições daquele garantido pela Caixa de Seguro-Doença.

Durante hospitalização ou internamento em sanatórios, suspende-se o auxílio-doença, passando o acidentado a ter direito a diárias (Tagegeld), correspondentes a $1 / 20$ da sua remuneração, com o mínimo de 0,65 DM. Nesta hipótese, os parentes que viviam sob dependência do segurado 
têm direito a auxílio familiar (Familiengeld), correspondente ao que receberiam a título de renda, se se tratasse de morte do acidentado.

b) Renda por incapacidade. Se após o decurso da 13. ${ }^{\text {a }}$ semana, ou a partir do dia em que cessar o pagamento do auxílio-doença, o acidentado apresentar incapacidade de, pelo menos, $20 \%$ terá direito a perceber renda mensal. Se a incapacidade fôr total, a renda será no valor de $2 / 3$ de sua remuneração no último ano anterior ao acidente, fixada entre limites mínimo e máximo (Vollrente). $\mathrm{Na}$ hipótese de incapacidade parcial igual ou superior a $20 \%$, recebe o acidentado parte da renda total, proporcional ao grau da perda de capacidade (Teilrente).

Quando a incapacidade fôr de $50 \%$ ou mais, é garantido ainda um suplemento de $10 \%$ da renda, para cada filho até que complete 18 anos de idade (ou 25 anos, para o $3 .^{\circ}$ filho e seguintes, quando êles se encontrarem sujeitos a trabalhos de formação profissional, ou não estiverem em condições de se manterem por si próprios, por causa de enfermidade ou defeito físico ou mental). Êsse suplemento denomina-se "Kinderzulage"

c) Rendas em caso de morte. Verificada morte em consequência de acidente do trabalho, os beneficiários recebem, além do auxílio funeral (Sterbegeld), as rendas de viuvez, orfandade ou de ascendentes, conforme o caso, a partir do dia da morte.

$O$ auxílio funeral corresponde a $1 / 15$ da remuneração anual do segurado, com o limite mínimo de $100 \mathrm{DM}$.

A viúva recebe, até sua morte ou novo casamento, uma renda no valor de $1 / 5$ da remuneração anual do acidentado, podendo ser de $2 / 5$, se ela já contar 45 anos de idade ou sofrer perda de, pelo menos, metade de sua capacidade de trabalho (Witwenrente).

$O$ viúvo, que era totalmente ou em grande parte mantido com o salário da espôsa vítima de acidente do trabalho, por estar incapacitado de trabalhar, tem direito a 
renda no valor de $2 / 5$ da remuneração anual da segurada (Witwerrente).

A renda dos filhos menores de 18 anos (ou do $3 .^{\circ}$ filho e seguintes, até 25 anos, quando se encontrarem em treinamento profissional ou estiverem, por enfermidade ou defeito físico ou mental, impossibilitados de se manterem por si próprios) corresponde a $1 / 5$ da remuneração anual para cada um (Waisenrente).

Os ascendentes mantidos com o salário da vítima têm direito, em conjunto, a uma renda no valor de $1 / 5$ da remuneração anual.

As rendas (que são pagas em parcelas mensais) percebidas por todos os beneficiários não devem ultrapassar, em conjunto, 4/5 da remuneração do acidentado.

Em determinados casos e sob certas condições, a lei alemã admite a substituição da renda por capital.

2. República Democrática Alemã. Embora não tenhamos conseguido os textos da legislação respectiva, daremos a seguir algumas informações sôbre a Alemanha Oriental, baseadas principalmente em artigos publicados na Revista Internacional do Trabalho.

As prestações em utilidades consistem, como na República Federal, nos cuidados médicos, inclusive de especialistas, na assistência dentária, farmacêutica, médico-cirúrgica e compreende também o fornecimento de aparelhos de prótese e o recolhimento em hospitais e sanatórios. Tais prestações são feitas por periodo ilimitado, salvo quanto à permanência em hospitais e sanatórios, que em geral não deve exceder de 26 semanas, mas pode prolongar-se, quando o médico atesta ser possível que o acidentado recobre sua capacidade de trabalho, até 52 semanas e, em casos excepcionais, até por mais tempo.

A partir do $10^{\circ}$ dia de incapacidade e até a $26 .^{\mathrm{a}}$ semana, recebe o acidentado, em dinheiro, importância correspondente a $50 \%$ do seu salário médio dos últimos 3 mêses 
anteriores ao acidente. Quando uma comissão médica entende possivel a recuperação da capacidade, êsse prazo pode ser prorrogado por mais 13 semanas.

Quando o segurado é empregado ou operário, o empregador deve pagar-lhe, durante o mesmo período, um suplemento correspondente à diferença entre o auxíliodoença e $90 \%$ do salário médio das 13 semanas anteriores à incapacidade.

Depois dêsse periodo inicial, se a incapacidade resultante do acidente fôr inferior a $20 \%$, nada mais receberá o acidentado. Se se tratar de incapacidade total, terá êle direito a uma pensão completa igual a $2 / 3$ do salário médio dos últimos 12 mêses, não podendo a média exceder 600 marcos. A pensão correspondente a incapacidade parcial igual ou superior a $20 \%$ é calculada proporcionalmente à pensão completa, de acôrdo com o grau da perda de capacidade para o trabalho.

A pensão pode também ser elevada em razão dos filhos, quando a incapacidade fôr de $50 \%$ ou mais. Assim, a cada filho menor de 15 anos (ou 18 anos, se fôr estudante dedicado exclusivamente aos estudos) corresponderá um aumento de $10 \%$ no valor da pensão.

A viúva considerada incapacitada para o trabalho tem direito a pensão igual a $40 \%$ do salário médio percebido pelo acidentado nos últimos 12 mêses. Considera-se a viúva incapaz quando tem um filho menor de 3 anos, ou dois menores de 8; quando sofre incapacidade para o trabalho superior a $66,66 \%$ ou já tiver completado 60 anos de idade. A pensão da viúva nos demais casos é de apenas $20 \%$ do salário médio.

No caso de órfãos de ambos os progenitores, menores de 15 anos (ou 18, quando estudante nas condições atrás indicadas), o filho mais velho tem direito a pensão de orfandade no valor de $30 \%$ do salário médio, sendo de $20 \%$ a pensão devida aos demais órfãos. 
Há ainda um suplemento mensal fixo de 10 marcos para as pensões de incapacidade total ou parcial superior a $66,66 \%$, para as das viúvas incapacitadas para o trabalho e para as dos órfãos de ambos os progenitores.

Os beneficiários, em conjunto, não podem perceber em caso algum mais de $80 \%$ do salário médio.

À vista do exposto, concluimos que são as seguintes as principais diferenças entre as indenizações previstas na lei brasileira e na alemã.

3. Prestações em utilidades. a) Não prevê a lei de acidentes brasileira indenização de dano material, mesmo que seja, como na República Federal da Alemanha, referente a aparelhos de prótese.

b) No Brasil tais prestações podem ser exigidas apenas durante o período de um ano a contar do acidente, ou até o pagamento, pelo empregador, da importância da indenização por incapacidade permanente, em que se tiver transformado a incapacidade temporária, por fôrça do art. 20 da lei. Na Alemanha, sempre que se entender possível a recuperação da capacidade do acidentado, poderão excepcionalmente ser ultrapassados os períodos fixados na lei.

4. Prestações em dinheiro. a) Estabelecido no Brasil, como limite máximo para cálculo de diária em caso de acidente, a importância correspondente a uma vez e meia o maior salário mínimo vigente (art. 44), e considerando que no momento atual certamente não são muito numerosos os salários superiores a Cr\$ $\$ 300,00$ diários, muitas vêzes é possível a percepção de indenização por incapacidade temporária igual ao salário da atividade.

Vimos que nas duas Repúblicas da Alemanha, excetuado o caso dos empregados da Alemanha Ocidental, é fixado sempre limite máximo para o auxílio-doença e os 
suplementos, de forma que, em caso algum, possam elevarse até o nível do salário.

b) Aqui, as diárias de incapacidade temporária e de incapacidade permanente, total ou parcial, são calculadas apenas tendo em vista o salário, de que constituem a $30 .^{\mathrm{a}}$ parte (Parágrafo único do artigo 19), variando a indenização por incapacidade permanente parcial de acôrdo com a natureza e gravidade da lesão, a idade e a profissão da vítima. Na Alemanha levam-se em consideração também os encargos de família.

c) Excetuado o regime de manutenção do salário, as indenizações por incapacidade permanente ou morte, previstas na Lei de Acidentes do Brasil, são tôdas de capital e só se transformam indiretamente em renda, através do acréscimo das aposentadorias e pensões. Na Alemanha, a regra é a indenização mediante pagamento de rendas mensais, que só excepcionalmente se transformam em capital.

d) No Brasil, a tôda incapacidade permanente corresponde a indenização de, pelo menos, $3 \%$ calculados sôbre 4 anos de diária, ao passo que na Alemanha não há indenização por incapacidade permanente inferior a $20 \%$.

e) Em nosso país, só a indenização por morte é que varia com os encargos de família, enquanto na Alemanha, como já referido, êsse elemento é considerado também em hipóteses de incapacidade.

\section{V - Justiça competente para conhecer causas sôbre acidentes do trabalho}

Na conformidade do $\S 10^{\circ}$ do art. 123 , da Constituição de 1946, os dissídios relativos a acidentes do trabalho são da competência da justiça ordinária no Brasil.

Na República Democrática Alemã tais dissídios cabem aos Tribunais do Trabalho, que são órgãos paritários e 
possuem Câmaras especiais para decidir sôbre questões de seguro.

$\mathrm{Na}$ República Federal da Alemanha, a competência é dos Tribunais Sociais, magistratura especial, inteiramente independente da Justiça do Trabalho e da Justiça comum.

\section{Bibliografia}

BLOCH, M. "Les Assurances sociales dans l'Allemagne d'après-guerre", in Revue Internationale du Travail, vol. 38, p. 330.

Block, F., SCharZer, H. e EbeLING, T. "Versicherungsfragen im Alltag" - Humboldt-Verlag-Frankfurt/M. Wien - 1954.

Cesarino JR., A.F "Direito Social Brasileiro" — $4 .{ }^{\mathrm{a}}$ ed. 1957.

CESARINo JR., A.F "O Estado e a Organização do Seguro em Matéria de Acidentes do Trabalho no Brasil" - Trabalho apresentado no II Congresso Internacional de Direito Social, organizado pelo Instituto Interuniversitário Belga de Direito Social - 1958 Bruxelas.

Dersch, H. "Der Staat und die Organisation der Unfallversicherung in der Bundesrepublik Deutschland" - Trabalho apresentado pelo A. como representante da Alemanha no mesmo Congresso acima.

NipPerdey, H. C. "Evolución del derecho laboral en la República Federal de Alemania desde 1945", in Revista Internacional del Trabajo — julho e agôsto de 1954.

ROHRBECK, W. - "Sozialversicherung ihr Wesen und ihre Bedeutung" Verlag Butzon \& Bercúer, Kevelär Rhld. 1950.

Zwicker-Scannevin, H. - "Terminologie der Sozialen Sicherheit", Verlag für Verwaltungspraxis Franz Rehm, München, 1956.

- "Evolución de la seguridad social en la República Federal de Alemania desde 1949, in Rev. Intern. del Trabajo - nov.-dez. 1952, p. 542 .

- "Evolución de los seguros sociales en la República Democrática Alemana desde 1949", ibidem nov. 1955, p. 502.

- “I.N.A.I.L. (Istituto Nazionale per l'Assiscurazione contro gli Infortuni sul Lavoro) - Rassegna della stampa periodica A.X n. ${ }^{\circ} 19-20$ - nov. 1957, p. 452 ; n. ${ }^{\circ} 21-22$ - nov.-dez. 1957, p. 533 - Roma. 
Ordenação n. ${ }^{\circ}$, de 26-7-52 - Nova lista de doenças profissionais da República Federal da Alemanha, in Série Legislativa, set.-out. 1954.

- "Übersicht über die Soziale Sicherung in der Bundesrepublik Deutschland" - Herausgegeben vom Bundesminister für Arbeit und Sozialordnung Generalsekretariat für die Sozialreform) 1958. 